\title{
The advantage of distributed practice in a blended learning setting
}

\author{
Nathanael S. Jost ${ }^{1} \cdot$ Sina L. Jossen ${ }^{1} \cdot$ Nicolas Rothen $^{1} \cdot$ Corinna S. Martarelli $^{1}$ \\ Received: 21 August 2020 / Accepted: 25 December 2020/ Published online: 5 January 2021 \\ (C) The Author(s), under exclusive licence to Springer Science+Business Media, LLC part of Springer Nature 2021
}

\begin{abstract}
Ongoing digital transformations facilitate the conduct of online courses and distance learning. In this study, it was aimed to investigate the role of learners' personalities and behaviors in their academic success (exam scores) in a blended learning setting (combination of distance learning and face-to-face learning). Next to individual differences in several variables (including intelligence), participants' $(n=62)$ learning time and learning motivation over 14 weeks (one term) using questionnaires for one learning module at the Swiss Distance University Institute was measured. Also, data on the participants' grades at the end of the course and the number of exercises they completed during the term were obtained. A stepwise regression analysis revealed that studying at the optimal time of the day and studying regularly are relevant predictors of academic success. The results and limitations of the study are discussed in the context of academic success prediction in higher education.
\end{abstract}

Keywords Learners' behaviors · Learners' personalities · Blended learning · Distance learning

\section{Introduction}

Academic success plays a crucial role in an individual's life and is of great societal relevance. Academic success, for example, enables further progress on one's academic path or access to occupational qualifications and is often used as a metric to assess institutional performance (Alyahyan and Düștegör 2020; Strenze 2007; Vermeulen and Schmidt 2008). The past two decades have been characterized by digital transformations (e.g., ubiquity of computers and network coverage) that facilitate the conduct of online courses and distance learning. Furthermore, the current situation related to

Corinna S. Martarelli

corinna.martarelli@fernuni.ch

1 Faculty of Psychology, Swiss Distance University Institute, 3900 Brig, Switzerland 
COVID-19 pandemic containment measures, including home confinement, social distancing, suspension of gatherings, and closing of schools, has exponentially increased the use of online courses and distance learning (Dietrich et al. 2020). It is predicted that there will be an even stronger uptick in interest in these learning modalities in the future. Academic success is a widely studied concept, but many studies that focus on the predicting variables of academic success have been tested in traditional learning settings without measuring actual behavioral pattern (ChamorroPremuzic and Furnham 2003; Giofrè et al. 2017; Kappe and van der Flier 2012; Lounsbury et al. 2003; Stadtfeld et al. 2019). In the current digital era, it is an indispensable step to identify learners' behaviors that relate to academic success in a blended learning setting.

Blended learning is an approach used in distance learning and combines online modes of learning (e.g., podcasts, materials and activities delivered online via learning platform systems) and offline modes of learning (e.g., face-to-face sessions at a given time in a physical classroom) (Bonk and Graham 2006). Online learning (compared with offline learning) is characterized by an individualization of learning, including aspects such as autonomy, flexibility, and use of multiple information and communication technologies (Lust et al. 2013). In a distance learning environment, students are more flexible and can therefore more strongly regulate their way of learning. For example, students can more easily adjust their study schedule to their needs, enabling them to distribute their learning over time more evenly instead of limiting it only to the period before an exam, and they can study at the time of the day that is optimal for them.

\section{Literature review}

Since the studies of Ebbinghaus (1885/1964; for a review, see, e.g., Donovan and Radosevich 1999; Greene 1989; Toppino and Bloom 2002), the beneficial effect of distributed practice - which implies a more spaced-out method of learning, with time intervals between study sessions - has largely been acknowledged. Indeed, distributed practice is one of the most powerful learner behaviors that positively impact academic success. It is also one of the most researched learner behaviors that has been replicated in experimental settings (Cepeda et al. 2006; Janiszewski et al. 2003) and applied settings (Cepeda et al. 2008; Kornell et al. 2010) alike. Current empirical evidence comes from learning analytics and data mining approaches, which highlight the importance of self-regulated learning (Tabibian et al. 2019; Viberg et al. 2020). Profiles of learners who study more regularly by following the sequential structure of a course, have been shown to gain a deeper understanding of the course materials (MaldonadoMahauad et al. 2018). Interestingly, Carvalho et al. (2020) showed that learners with higher cognitive abilities as well as learners that engage more with the course were more likely to distribute their learning. However, it is the learners with lower abilities as well as learners that engaged less with the course that benefitted most from distributed practice (Carvalho et al. 2020). Further, several studies suggest that morning-type individuals are more successful with regard to academic achievement (Beşoluk et al. 2011; Preckel et al. 2013). By contrast, there are no significant differences between morning- and evening-type students in a distance learning setting (Horzum et al. 2014), 
suggesting that online learning can be used to reduce the asynchrony problem faced in traditional learning settings (e.g., evening-type students having to attend lectures during mornings and afternoons). Other indicators of learning behavior have been shown to predict academic success, such as the number of hours of studying (see, e.g., Barbarick and Ippolito 2003).

Next to learners' behaviors, learners' intelligence and personality have been investigated. Previous research has strongly focused on the relationship between intelligence and academic success (e.g., Deary et al. 2007; Touron 1983; Walberg 1984) and cognitive abilities have been identified as the most important and fundamental factor of academic success (Rohde and Thompson 2007). To a lesser extent, there have been efforts to investigate the impact of non-performance-based personality constructs on academic success, such as the impact of the Big Five personality dimensions (e.g., Trapmann et al. 2007), anxiety (Silva et al. 2007), self-control (Zhu et al. 2016) or confidence-related constructs, such as self-esteem (Giofrè et al. 2017). These constructs have been shown to affect academic success and thus to be theoretically relevant.

\section{Aim of the study, objectives, and contribution to knowledge}

Several learners' characteristics have been shown to impact academic success. Given that blended learning is linked to behavioral flexibility, productive learners' behaviors need to be characterized and their learning practices need investigation in the context of a blended learning setting, by taking into account the influence of personality variables. Existing studies are frequently carried out in traditional learning settings and focus on selected variables, thus neglecting a comprehensive investigation of individual differences in both learners' personalities and behaviors as predictive variables of academic success beyond intelligence. The main aim of the present study was to assess the most influential predicting variables for academic success in the context of a blended learning setting in higher education. ${ }^{1}$ We were especially interested in whether distributed practice would show a substantial advantageous effect on academic success in the context of a blended learning setting. Moreover, we were interested in testing whether learning at the optimal time of the day (on-peak: morning for morning types and evening for evening types) versus learning at the non-optimal time of the day (offpeak: evening for morning types and morning for evening types) affects academic success in a distance learning scenario. Based on Horzum et al. (2014), we hypothesized that the degree of on-peak learning is positively correlated with academic success. To assess learners' behaviors, the total number of hours of studying, the time of the day devoted to studying, and the regularity of studying were collected. Next to learning practices a further important construct that has been shown to contribute to academic success is learners' motivation and engagement with learning (Cho and Heron 2015; Lee et al. 2019). Therefore, the weekly motivation was also assessed and a positive correlation between motivation and academic success was hypothesized.

\footnotetext{
${ }^{1}$ This study was pre-registered (https://aspredicted.org/4kw2a.pdf). Contrary to our pre-registration, we tested the hypotheses in one learning module and did not attempt to replicate the results across modules with different learning contents. We address this point in the limitation section of the discussion.
} 
Next to learners' behaviors it was aimed to assess learners' personality. Based on the relationships of variables presented above, the included learners' personality variables were self-esteem, self-control, trait anxiety, chronotype, and the Big Five dimensions. Considering the important role of intelligence shown in previous studies (e.g., Tias et al. 2015), also intelligence was measured. As dependent variable the points obtained at the final exam of one learning module were used as a measure of academic success.

To investigate and confirm these findings, the following research question was proposed: Are the most substantial indicators of academic success of behavioral nature and thus go beyond the influence of personality and intelligence in a behaviorally flexible blended learning setting? To obtain a better understanding of the complex learning processes, it is essential to consider these different aspects of learners simultaneously. The findings have relevant practical as well as theoretical implications regarding distance education e.g., to allow more effective personalized support during the learning process.

\section{Methods}

\subsection{Participants}

An a priori $\mathrm{G}^{*}$ Power analysis revealed that we needed a sample of 40 participants to detect at least a medium effect (linear multiple regression, fixed model, single regression coefficient, input parameters: $f^{2}=.35, \alpha=0.05,1-\beta=.95$; Faul et al. 2007). The estimation of the expected effect size was based on a previously observed strong positive relation between the number of exercises that students completed during one term and their exam scores (unpublished data observed during three previous terms, $r(84)=.514, p<.001$ ). The final sample consisted of 62 university students $\left(M_{\text {age }}=36.56, S D_{\text {age }}=7.91 ; 79.03 \%\right.$ female $)$ enrolled in a statistical psychology course at the Swiss Distance University Institute (autumn term 2018 and spring term 2019). They were studying psychology at the Swiss Distance University Institute, and their occupations were classified as technicians (3.23\%), sales staff (4.84\%), executives $(9.68 \%)$, social and health services staff $(16.13 \%)$, teaching $(17.74 \%)$, service sector staff $(27.42 \%)$, and others (e.g., parenthood, professional sportsperson) (20.97\%). The participants reported having an employment rate ranging from $0 \%$ to $100 \%(M=62.90, S D=33.70)$, and $40.32 \%$ of the participants reported having at least one child. Moreover, their highest level of education was assessed, and $59.68 \%$ of the participants reported having another university degree.

All students enrolled in the course $(N=101)$ were contacted and had to take part in the study (but were free to choose whether we could use the data for scientific purposes). As the course was about methods and statistics, this was a good opportunity for the students to gain insights into research methods. We discussed one topic of the course (i.e., multiple linear regression) with a simulated dataset containing the exact variables we assessed. Out of the 101 students, 25 de-registered from the course early and thus did not fully participate in the study, 11 did not agree to the use of their data for scientific purposes, 2 had to be excluded because they displayed clear outlier values on the dependent variable (based on deleted studentized residuals ${ }^{2}$ ), and 1 participant

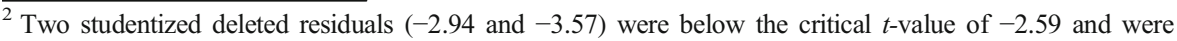
therefore removed.
} 
was excluded because of an outlier on the IQ distribution (IQ = 58). The study was approved by the university's local ethics committee and was carried out in accordance with the Declaration of Helsinki of 1975. All person gave their written informed consent prior to their inclusion in the study.

\subsection{Design, procedure, and materials}

The study was conducted during a second-term course on statistics (two times: autumn 2018 and spring 2019); the instructor for the course was the last author of this paper. The course was given in a blended learning setting. In the first week of the online course, the first meeting took place, in which the students were informed about the study procedure. Those students who did not attend this session received the information via email. We asked the students to fill out a questionnaire assessing different aspects of their personality (including an intelligence test). They were contacted each week (over 14 weeks) to report their motivation and learning time and the resources they invested in for the course. The study design is depicted in Fig. 1.

Learning materials and course requirements Learning materials were presented online in the web-based Moodle platform (moodle.org). The course contained learning materials for 14 weeks. For each week, a statistical theme was treated (e.g., analysis of variance). The students had access to a script (summary of recommended book chapters) and a series of exercises. To encourage distributed learning, we provided five series of exercises that were obligatory for the students to be able to register for the exam. At the end of each week, all students received the solution of the weekly exercises, and those who submitted their solution received detailed feedback from a teaching assistant.

Five meetings with the students took place during the semester (every three weeks). They had to attend three out of the five meetings in order to register for the exam. The final exam was the only graded coursework that the students had to pass. This exam, which was held at the end of the term, took place in a room on campus under the supervision of a teaching assistant. The students had two hours to work on the exam (open questions), and the maximum number of possible points was 50 .

Questionnaires assessing personality and intelligence Individual differences in the selected variables were recorded using a questionnaire. All questionnaires were administered on a computer or mobile device (online questionnaires using the software Unipark, https://www.unipark.de/. After giving or withdrawing their consent to use their collected data for research purposes, the participants worked on five personality questionnaires, which were presented in randomized order, followed by an intelligence test. Finally, the participants provided their demographic information (age, sex, highest level of education, employment, number of children). Higher overall scores on all the questionnaires indicate higher values of the respective variable.

Neuroticism, openness, agreeableness, extraversion, and conscientiousness were assessed with the 15-item Big Five Inventory-SOEP (BFI-S; Schupp and Gerlitz 2014). We used Schupp and Gerlitz short form of the Big Five Personality Inventory-SOEP to assess the relation between academic success and personality. The inventory measures personality in terms of the five dimensions of neuroticism (e.g., "I am someone who worries a lot"), openness (e.g., "I am someone who is 


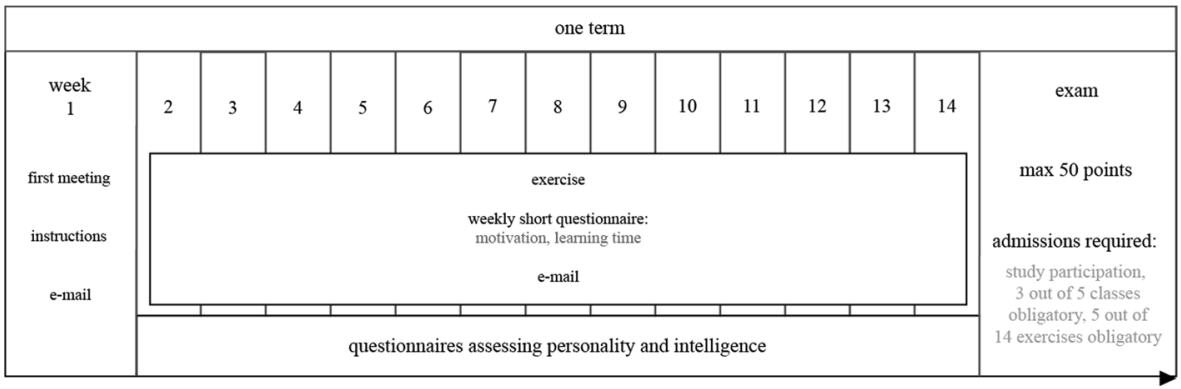

Fig. 1 Graphical representation of the study design

original and brings new ideas"), agreeableness (e.g., "I am someone who can forgive"), extraversion (e.g., "I am someone who is communicative and talkative"), and conscientiousness (e.g., "I am someone who works thoroughly"). The scale consists of 15 items. Its reliability, validity, and dimensionality have been confirmed (Schupp and Gerlitz 2014). The participants answered on seven-point Likert-type scales $(1=$ disagree strongly to 7 = agree strongly). The mean score for each participant for each dimension was computed. Internal consistency of each dimension was sufficient. Cronbach's alphas were .82 (neuroticism), .75 (openness), .48 (agreeableness), .85 (extraversion), and .61 (conscientiousness).

The German multidimensional Self-Esteem Scale (MSWS; Schütz and Sellin 2006) consists of six subscales. To assess a possible relationship between self-esteem and academic success, we used the four subscales of ESWS (emotional self-esteem), SWKO (social selfesteem regarding security in contact), SWKR (social self-esteem while dealing with criticism), and LSWS (performance-related self-esteem). We did not include the subscales SWPA and SWSP, which measure self-esteem related to physical features. The MSWS has good psychometric properties with retest reliabilities for the four subscales used in the present study ranging from .76 to .87 and Cronbach's alphas ranging from .69 to .82 (Schütz et al. 2017). General self-esteem was thus assessed with the selected four subscales consisting of 22 items in total (e.g., "Do you doubt yourself?") rated on seven-point Likerttype scales $(1=$ not at all to $7=$ very much $)$. A mean response score for self-esteem was computed for each participant. Cronbach's alpha was .88.

The participants also worked on the German short version of the Self-Control Scale (SCS-K-D; Bertrams and Dickhäuser 2009). The SCS-K-D measures individuals' general ability to regulate themselves. The SCS-K-D consists of 13 items (e.g., "I am good at resisting temptations"), which are answered on five-point Likert-type scales ( $1=$ not at all to $5=$ very much). The SCS-K-D is an established instrument that has been used in various contexts (e.g., education, sports, experimental psychology). A mean response score for selfcontrol was computed for each participant. Cronbach's alpha was .86.

The State-Trait-Anxiety-Depression-Inventory (STADI; Laux et al. 2013; Renner et al. 2016) consists of two subscales (measuring anxiety and depression), including trait and state aspects. We focused on trait anxiety by using the two sub-scales, Nervousness and Concern, each including five items (e.g., "My nerves are tense," "I worry about problems that could come up"). Latent trait modelling showed that the STADI is able to differentiate between state and trait anxiety, which was ideal given our interest in personality characteristics and thus in the trait aspect of anxiety (Laux 
et al. 2013). Furthermore, the STADI has good psychometric properties with Cronbach's alphas ranging from .81 to .86 (Laux et al. 2013). Answers were given on four-point Likert-type scales $(1=$ almost never to $4=$ almost always $)$. A mean response score for anxiety was computed for each participant. Cronbach's alpha was .85 .

The German Morningness-Eveningness-Questionnaire (D-MEQ gives indications about the chronotype of a person. The MEQ provides an economic yet valid way to measure an individual's chronotype. The questionnaire was validated by correlating its results with the daily lowest bodily temperature of the subjects and the daily onset of melatonin production and found highly significant correlations. Retest reliabilities of the D-MEQ lie over .95 (Griefahn et al. 2001). The D-MEQ consists of 19 items with single-choice answers (e.g., "At approximately what time of the day do you usually feel your best?"). A mean response score for the sole dimension was computed for each participant.

After the personality questionnaires were administered in random order, the participants completed the Culture Fair Test-Revised (CFT 20-R; Weiss 2006). The CFT 20-R measures fluid intelligence with the subtests Series Continuation, Classification, Matrices, and Topological Conclusions. Crystal intelligence was measured with two additional tests (Vocabulary and Numerical Sequence). The CFT 20-R is generally considered a valid culture fair test that has been widely used in studies predicting academic success, especially when predicting mathematical abilities; correlations between CFT 20-R scores and math grades have been shown to be higher than correlations between the test scores and for example language grades (Weiss 2006). The CFT-20-R has good psychometric properties with retest reliabilities ranging from .80 to .90 (Weiss 2006). A mean response IQ score was computed for each participant. Cronbach's alpha was .56.

Weekly short questionnaire The students were contacted each week (over 14 weeks) to report their motivation and learning time for the course. Weekly motivation was measured with four questions on intrinsic motivation ("This week, I am studying because I find the topic very interesting"), extrinsic motivation ("This week, I am studying because I want to pass the exam"), self-efficacy ("This week, I can remain calm when facing learning difficulties because I can rely on my abilities"), and situational stress ("This week, I have worries and duties other than studying"), rated on fivepoint Likert-type scales $(1=$ totally true to $5=$ not at all true $)$. The students also indicated the time (hours) they spent studying and/or working for the course during the week (morning, noon, afternoon, evening, and night for each day of the week). We assessed the time of the day the students studied to investigate the impact of studying at the optimal time of the day (see the on-peak time variable below). The students also reported the consulted resources, such as course materials (e.g., slides [39.87\%], online platforms [25.92\%], supplementary exercises [13.40\%], and other resources, examples of which are online resources, such as YouTube [4.00\%], learning materials, such as textbooks [2.87\%], peer-to-peer discussions [1.65\%], lectures [0.16\%], none [5.42\%], forums [4.25\%], and contact with lecturers [2.98\%]). Lastly, students who were not motivated were asked to give a reason and choose between the following options: no time or other obligations $(83.25 \%)$, no motivation to study $(4.71 \%)$, and other reasons with an open answer (illness [8.90\%], technical difficulties [2.09\%], and subject difficulty [1.05\%]). 


\section{Results}

The main purpose of the study was to investigate the role of learners' personalities and behaviors in their academic success (exam score) in a blended learning setting. We report the descriptive statistics and a stepwise regression analysis with exam scores as the dependent variable. Given the explorative nature of our study, the large number of variables assessed, and the relatively small sample size, we decided to conduct a stepwise regression analysis. More details about this analysis are reported below. All computations in the analyses used jamovi (The Jamovi Project, 2019) and $R$ (R core Team 2019). The main analyses were conducted with the functionalities of the MASS (Venables and Ripley 1994) and MICE (van Buuren and Groothuis-Oudshoorn 2011) packages. The $R$ code to reproduce the main analysis is available on OSF (https://osf.io/ wn2tp/). The datasets that support the findings of this study are not publicly available due to privacy concerns (the information could compromise the privacy of the participating students, see variables such as gender, age, exam score, and intelligence score). The datasets are available from the corresponding author (C.S.M.) on reasonable request.

\subsection{Prediction of exam scores with learners' personality and behavior variables}

Handling missing data Exploration of the data revealed $8.06 \%$ of missing values on the dependent variable as well as on the number of exercises completed in one term. Additionally, one missing value on the variable self-control was identified. The other variables showed no missing values. As $8.06 \%$ of values were missing and it has been suggested to impute variables instead of using listwise deletion when variables have more than 5\% missing values (Azur et al. 2011), we used multivariate imputation by chained equations (MICE) following the general recommendations of Azur et al. (2011) (for an overview of the different methods to handle missing data, see, e.g., Horton and Kleinman 2007). The MICE procedure included four general steps. First, a mean imputation was computed for every missing variable. After the mean imputed values of one variable were set back to the missing values, these missing values were estimated using multiple regression; every other variable in the dataset was used as a predictor. The estimations of the mean values that were previously missing were used as real values for the estimation of missing values on other variables. These steps were performed for both variables with missing values, which, in turn, constituted one iteration cycle. Ten iteration cycles were performed; the imputations were updated each cycle (Azur et al. 2011).

Variable properties and computation To quantify learners' behavior, we created the variables hours studied, on-peak time, number of days, and studying regularity. The variable hours studied represents the total amount of time that the students invested in the course, including studying and completing exercises. The variable on-peak time indicates the amount of time (in percentage) that the students spent studying in the time frame congruent with their chronotype. To code chronotype, we used a mean-split approach of the D-MEQ population distribution and coded students either as morning types (values $>50$ ) or evening types. As there were many students with scores between one standard deviation above and below 50, we further validated the classification by 
evaluating the last item of the D-MEQ (i.e., "One hears about 'morning' and 'evening' types of people. Which one of these types do you consider yourself to be?"), in which students were asked whether they would label themselves as a morning or evening type of person. Of the students, $83.87 \%$ classified themselves consistent with our classification (for a validation of this method, see also Rothen and Meier 2016). We then calculated the mean percentage (across all study days) of time the students spent studying in the morning and noon or in the evening and night for the morning and evening types, respectively.

Number of days is the total number of days that the students spent at least $30 \mathrm{~min}$ studying or completing exercises. Studying regularity is a measure for quantifying the regularity of studying behavior. We computed the standard deviation of daily study time for each student. Students with low values on this variable tend to study more regularly. However, we did not include the days on which the students did not study because we wanted to consider the number of days separately (see above). Even though studying regularity, hours studied, and number of days are all indicators of massed versus distributed learning behavior, it is important to note that one cannot interpret them separately with respect to the distribution of learning behavior.

Descriptive statistics We computed Cronbach's alpha and McDonald's omega for the internal consistency of the scales. In contrast to Cronbach's alpha, McDonald's omega does not assume essentially tau-equivalent items but allows different factor loadings of items on the common factor (Dunn et al. 2014). The internal consistency of the scales and the descriptive statistics are reported in Table 1. All scales showed sufficient internal consistency; skewness and kurtosis were small. All correlations are reported in Appendix A.

Visual inspection After visual inspection of the data, anxiety and total hours studied showed polynomial quadratic relationships with the dependent variable (see Appendix Fig. 3 for an illustration of the data). Thus, quadratic terms were included in the main analysis. All other variables showed linear trends or no recognizable pattern (see Appendix Fig. 3).

Main analysis Given our exploratory approach and small students-predictor ratio, we conducted a stepwise regression analysis to identify all relevant predictors of academic success. All variables shown in Table 2, as well as gender and age, were entered into the initial model. One major concern with stepwise regression techniques and specifically with the present data is the risk of overfitting. To address this issue, we conducted a stepwise regression by eliminating non-substantial predictors based on the Bayesian Information Criterion (BIC). As a model selection method, BIC has been criticized to penalize models with large sample sizes too heavily (e.g., James et al. 2013); because of our small sample, this should not be an issue. Additionally, compared with the Akaike Information Criterion (AIC), BIC tends to be preferable in studies that favor a type 2 over a type 1 error, as AIC tends to favor an overfitted selected model (Kass and Raftery 1995). In view of our exploratory approach, we therefore chose BIC as our criterion selection procedure. All predictors shown in Table 2 revealed a substantial influence except for the linear effect of how many hours students studied, which was added because it is the lower-order polynomial term of the quadratic predictor of hours 
Table 1 Descriptive summary of the measures

\begin{tabular}{llccccc}
\hline & Measure (N) & Mean (SD) & Skewness & Kurtosis & Alpha & Omega \\
\hline \multirow{2}{*}{ Learners' personality } & Self-esteem (62) & $50.29(10.12)$ & -0.12 & -0.87 & .88 & .88 \\
& Self-control (62) & $3.52(0.67)$ & -0.33 & -0.9 & .86 & .86 \\
& Anxiety (62) & $50.65(11.86)$ & -0.21 & -0.87 & .85 & .86 \\
& Chronotype (62) & $56.89(11.18)$ & -0.35 & -0.79 & - & - \\
& Intelligence (62) & $115.69(13.61)$ & -0.28 & -0.85 & .56 & .59 \\
& Neuroticism (62) & $3.88(1.59)$ & -0.04 & -1.07 & .82 & .82 \\
& Extraversion (62) & $4.55(1.42)$ & -0.2 & -1.08 & .85 & .86 \\
& Conscientiousness (62) & $5.56(0.96)$ & -0.89 & 0.61 & .61 & .63 \\
& Agreeableness (62) & $5.68(0.82)$ & -0.77 & 0.2 & .48 & .62 \\
& Openness to experience (62) & $5.34(1.08)$ & -0.6 & -0.63 & .75 & .75 \\
Tearners' behaviors & Total hours (62) & $90.71(52.53)$ & 0.73 & 0.49 & - & - \\
& Number of days (62) & $31.79(17.75)$ & 0.85 & 0.85 & - & - \\
& Motivation (62) & $2.67(0.5)$ & -0.24 & -0.82 & - & - \\
& Studying regularity (SD) (62) & $2.73(1.28)$ & 1.03 & 1 & - & - \\
& Number of exercises (62) & $9.47(3.1)$ & -0.13 & -1.35 & - & - \\
& On-peak time (\%) (62) & $43.53(21.45)$ & 0 & -0.75 & - & - \\
& Exam score (62) & $38.35(7.09)$ & -0.28 & -0.85 & - & - \\
\hline
\end{tabular}

Note. There was a maximum possible score of 50 points in the exam. Descriptive measures of intelligence represent the means of all six subscales (see above). One value of self-control, five values of number of exercises, and five values of exam score were imputed (see above)

studied. ${ }^{3}$ Comparing a full regression model with all input variables as predictors (all variables in Table 1 as well as age and gender) with the selected model revealed a substantial $\triangle \mathrm{BIC}$ of $37(\triangle \mathrm{AIC}=8)$. Except for the quadratic predictor and its linear term, the collinearity statistics of the selected model indicated no problematic multicollinearity (all variance inflation factors $<4$ ). The model fit measures are reported in Table 3.

\section{Discussion}

This study had two aims: to replicate the advantage of distributed practice in a blended learning setting and to explore the impact of learners' personalities and behaviors on their academic success. Consistent with our observation in previous terms, our study showed an effect of studying regularity, suggesting that academic success is higher when students study regularly in a distance learning environment (see, e.g., Lim 2016). Distance learning settings are characterized by flexibility, and compared with traditional learning environments, they allow students to more easily organize their study

\footnotetext{
${ }^{3}$ In the multiple regression equation, the lower order polynomial term can only be omitted if the vertex of the parabola of the quadratic term is located exactly at $\mathrm{x}=0$, which is not the case here, therefore the linear term of hours studied has to be included in the current analysis.
} 
schedule. Despite the flexibility of distance learning (and the intuitive idea of ondemand courses), however, the regular scheduling of learning activities appears crucial to foster academic success in this learning setting. Next to studying regularity, other behavioral variables emerged as relevant predictors. For example, studying at the optimal time of the day (congruent with one's own chronotype) also had a beneficial effect on academic success. This finding is interesting and might point out an aspect that is neglected when assessing behavioral practices that foster learning. It also highlights the advantage of distance learning, which enables students to avoid the asynchrony problem with regard to learning times and enables them to learn at the time of their peak performance (cf. also Horzum et al. 2014). The number of days the students studied was also chosen by the stepwise regression method and revealed an inverse relationship with academic success. However, this predictor did not reach statistical significance $(p=.17)$ and one should be careful when interpreting this variable individually as it varies with studying regularity and total hours studied, their zero-order correlations being $r=.33$ and $r=.75$, respectively (see Appendix Fig. 2). Finally, hours studied had a quadratic impact on academic success (significant by trend), with students studying for many hours and students studying for a few hours showing the best performance in the exam. This finding is in line with previous research (see, e.g., Masui et al. 2014; Plant et al. 2005).

In this study, learners' behaviors had a substantial impact on academic success (the model explains $24 \%$ of the variance), whereas learners' personalities appeared to play a smaller role. Indeed, all the personality variables were not selected by our statistical approach. In the next section, we discuss the reasons that might explain these findings.

The variables that were not selected by the stepwise regression were age, gender, intelligence, self-esteem, motivation, anxiety, self-control, and the Big Five dimensions. Intelligence has been considered one of the most substantial predictors for academic success (Giofrè et al. 2017; Tias et al. 2015), but several studies have also found the strength of the relationship between intelligence and academic success to vary among grade levels, with higher education showing the smallest relationship between the two constructs; the argument is that at each educational level, the worst students drop out, thus restricting the variance of the IQ distribution that results in lower correlations (Jensen 1998). Indeed, the IQ distribution of our student sample shows a mean IQ of 115.69 (see Table 1), one standard deviation above average. We

Table 2 Coefficients of the stepwise regression model

\begin{tabular}{|c|c|c|c|c|c|c|c|}
\hline \multirow[t]{2}{*}{ Predictor } & \multirow[t]{2}{*}{ Estimate } & \multirow[t]{2}{*}{$\mathrm{SE}$} & \multicolumn{2}{|c|}{$95 \%$ Confidence Interval } & \multirow[t]{2}{*}{$\mathrm{t}$} & \multirow[t]{2}{*}{$\mathrm{p}$} & \multirow[t]{2}{*}{ Stand. Estimate } \\
\hline & & & Lower & Upper & & & \\
\hline Intercept & 40.24 & 3.21 & 33.81 & 46.67 & 12.53 & $<.001$ & \\
\hline Hours studied & -0.03 & 0.06 & -0.15 & 0.10 & -0.44 & 0.659 & -0.21 \\
\hline Hours studied squared & $3.88 \mathrm{e}-4$ & $2.18 \mathrm{e}-4$ & $-4.88 e^{-5}$ & $8.24 \mathrm{e}-4$ & 1.78 & 0.081 & 0.67 \\
\hline Number of days & -0.13 & 0.09 & -0.31 & 0.06 & -1.39 & 0.170 & -0.32 \\
\hline Studying regularity & -1.73 & 0.77 & -3.28 & -0.18 & -2.24 & 0.029 & -0.31 \\
\hline On-peak time & 11.46 & 3.91 & 3.63 & 19.30 & 2.93 & 0.005 & 0.35 \\
\hline
\end{tabular}

Note. $\mathrm{N}=62$ 
Table 3 Fit measures of the stepwise regression model

\begin{tabular}{|c|c|c|c|c|c|c|c|c|}
\hline \multirow[b]{2}{*}{ Model } & \multirow[b]{2}{*}{$\mathrm{R}$} & \multirow[b]{2}{*}{$\mathrm{R}^{2}$} & \multirow[b]{2}{*}{ AIC } & \multirow[b]{2}{*}{$\mathrm{BIC}$} & \multicolumn{4}{|c|}{ Overall Model Test } \\
\hline & & & & & $\mathrm{F}$ & df1 & $\mathrm{df} 2$ & $\mathrm{p}$ \\
\hline Stepwise & 0.49 & 0.24 & 414.87 & 429.76 & 3.46 & 5 & 56 & 0.009 \\
\hline
\end{tabular}

therefore suggest that IQ did not predict academic success in our sample, as it did not contain enough students with a below-average IQ, meaning that most of the students met and exceeded IQ requirements for the course to an extent that IQ would no longer predict academic success. Although there is some evidence showing the positive impact of self-esteem on academic success (Giofrè et al. 2017), a meta-analysis only found a small overall effect $(r=.08)$ of positive self-beliefs on academic success (Valentine et al. 2004). It is important to mention that we did not assess academic self-esteem but general self-esteem. The authors report inconsistent findings when considering different dimensions of self-esteem (see, e.g., Pullmann and Allik 2008). Previous research also found an impact of motivation (Busato et al. 2000; Komarraju et al. 2009) and anxiety (Erzen 2017; King et al. 1976; Silva et al. 2007) on academic success, as well as of selfcontrol (Tangney et al. 2004; Zhu et al. 2016) and conscientiousness (Busato et al. 2000; Chamorro-Premuzic and Furnham 2003; Giofrè et al. 2017; Kappe and van der Flier 2012; Noftle and Robins 2007; Poropat 2009). Our methodological and statistical approach can explain these inconsistent findings. As motivation was assessed weekly, the students might not have answered the motivational questions diligently; indeed, motivation showed a negative correlation with how many exercises the students completed in our dataset ( $r=-.20$; see Appendix Fig. 2). Motivation was also negatively correlated with conscientiousness $(r=-.27$; see Appendix Fig. 2), possibly reflecting an acquiescence bias in demotivated students. Openness, agreeableness, neuroticism, and extraversion were not selected by the stepwise regression either. This finding is consistent with a meta-analysis that analyzed over 250 correlation coefficients and did not find any impact of these four personality dimensions on the academic success (i.e., grades) of students in German universities (Trapmann et al. 2007), perhaps ultimately reflecting an unbiased teaching style because, for example, more extraverted students did not show any advantage. Trapmann et al. (2007) found a positive impact of conscientiousness on academic success, whereas in our study, conscientiousness was not selected. Surprisingly, self-control was not selected either, whereas previous research has pointed out self-control as one of the most important self-regulatory strategies necessary to succeed in higher education, in general (Puzziferro 2008), and in distance learning, in particular (Radovan 2011; Zhu et al. 2016). Overall, the results are encouraging, as they highlight that study strategy might be more important than personality variables, such as intelligence.

Finally, learners' personality variables were related to behavioral variables (see Appendix Fig. 2), thus suggesting that these variables might very well play an indirect role in academic success. Generally, we want to draw attention here to the fact that variables must be interpreted in relation to the other variables selected in the model. One of the strengths of this study is its extensive inquiry into the personality and behavioral variables of students; while there is comprehensive literature on various 
single variables and constructs in relation to academic success, few studies have considered personality and behavioral influences exhaustively. It is important to note here that we do not suggest personality variables to be uninfluential on academic success; rather, we propose that in a blended distance learning setting in higher education, behavioral variables, such as using effective learning strategies, may outweigh the impact of personality on academic success.

Some limitations of the study should be considered when interpreting the findings. First, a larger number of samples should be tested to replicate the findings, and these findings must be tested in other contexts. Future research would benefit from examining the generalizability of the results in more detail by using other samples and other learning materials. Second, we defined academic success narrowly by reducing it to exam scores (Busato et al. 2000; Hair and Hampson 2006; Lounsbury et al. 2003). As others before us have pointed out (Kappe and van der Flier 2012; York et al. 2015), academic success is a multi-faceted concept that includes other aspects, such as attainment of learning outcomes (ChamorroPremuzic and Furnham 2003), career success (York et al. 2015), or satisfaction (Lo 2010; York et al. 2015). Future research would benefit from integrating these other aspects. Third, we privileged ecological validity, which can be threatened by factors such as selection bias. Indeed, $24.75 \%$ of the students de-registered from the course (drop-out) and did not complete our study.

\section{Conclusion}

Since the beginning of the digital era, the use of online learning tools and digital approaches has increased remarkably, an effect which has recently been amplified by the current COVID-19 pandemic. In response to the COVID-19 situation, new approaches of online learning are emerging and future interest in the topic is striking. To optimize learning efficiency and minimize teaching bias, however, it is paramount to investigate variables predicting academic success in such settings. Various previous studies showed personality traits, cognitive abilities as well as learning behavior to be crucial determinants for academic success in face to face on-campus settings. Given the high levels of autonomy and flexibility in a blended learning setting, learners' behaviors could prove especially crucial for academic success. The present study sought to identify the most essential predictors for academic success in a blended learning setting taking both learners' personalities and behaviors into account. In summary, this work provides an important initial contribution by showing the predicting variables of academic success in a blended learning setting. Behavioral variables seem to be the essential contributors to academic success in a model that also considers personality and intelligence. Foremost, distributed practice at the optimal time of the day seems to be the key to academic success. This is very much in line with the notion that distance learning is a successful approach to reduce the asynchrony problem. We hope that this study will inspire further research to better understand the predicting variables of academic success in the digital era we are living in. 
Author's contribution C.S.M., N.R., and S.J. conceived the presented idea. S.J. and C.S.M. prepared the study and collected the data. N.J. and C.S.M. performed the analyses. C.S.M., N.J., and S.J. wrote the manuscript. C.S.M. supervised the project and all authors discussed the results and contributed to the final manuscript.

\section{Compliance with ethical standards}

Competing interests The authors declare no competing interests.

\section{References}

Alyahyan, E., \& Düștegör, D. (2020). Predicting academic success in higher education: Literature review and best practices. International Journal of Educational Technology in Higher Education, 17(1), 3. https:// doi.org/10.1186/s41239-020-0177-7.

Azur, M. J., Stuart, E. A., Frangakis, C., \& Leaf, P. J. (2011). Multiple imputation by chained equations: What is it and how does it work? International Journal of Methods in Psychiatric Research, 20(1), 40-49. https://doi.org/10.1002/mpr.329.

Barbarick, K. A., \& Ippolito, J. A. (2003). Does the number of hours studied affect exam performance? Journal of Natural Resources and Life Sciences Education, 32(1), 32-35. https://doi.org/10.2134/jnrlse. 2003.0032 .

Bertrams, A., \& Dickhäuser, O. (2009). Messung dispositioneller Selbstkontroll-Kapazität: Eine deutsche Adaptation der Kurzform der Self-Control Scale (SCS-K-D). Diagnostica, 55(1), 2-10. https://doi.org/10. 1026/0012-1924.55.1.2.

Beșoluk, Ș., Önder, İ., \& Deveci, İ. (2011). Morningness-eveningness preferences and academic achievement of university students. Chronobiology International, 28(2), 118-125. https://doi.org/10.3109/07420528. 2010.540729.

Bonk, C. J., \& Graham, C. R. (Eds.). (2006). Handbook of blended learning: global perspectives, local designs. San Francisco, CA: Pfeiffer Publishing.

Busato, V. V., Prins, F. J., Elshout, J. J., \& Hamaker, C. (2000). Intellectual ability, learning style, personality, achievement motivation and academic success of psychology students in higher education. Personality and Individual Differences, 29(6), 1057-1068. https://doi.org/10.1016/S0191-8869(99)00253-6.

Carvalho, P. F., Sana, F., \& Yan, V. X. (2020). Self-regulated spacing in a massive open online course is related to better learning. Npj Science of Learning, 5(1), 2. https://doi.org/10.1038/s41539-020-0061-1.

Cepeda, N. J., Pashler, H., Vul, E., Wixted, J. T., \& Rohrer, D. (2006). Distributed practice in verbal recall tasks: A review and quantitative synthesis. Psychological Bulletin, 132(3), 354-380. https://doi.org/10. 1037/0033-2909.132.3.354.

Cepeda, N. J., Vul, E., Rohrer, D., Wixted, J. T., \& Pashler, H. (2008). Spacing effects in learning: A temporal ridgeline of optimal retention. Psychological Science, 19(11), 1095-1102. https://doi.org/10.1111/j.14679280.2008.02209.x.

Chamorro-Premuzic, T., \& Furnham, A. (2003). Personality predicts academic performance: Evidence from two longitudinal university samples. Journal of Research in Personality, 37(4), 319-338. https://doi.org/ 10.1016/S0092-6566(02)00578-0.

Cho, M.-H., \& Heron, M. L. (2015). Self-regulated learning: The role of motivation, emotion, and use of learning strategies in students' learning experiences in a self-paced online mathematics course. Distance Education, 36(1), 80-99. https://doi.org/10.1080/01587919.2015.1019963.

Deary, I. J., Strand, S., Smith, P., \& Fernandes, C. (2007). Intelligence and educational achievement. Intelligence, 35(1), 13-21. https://doi.org/10.1016/j.intell.2006.02.001.

Dietrich, N., Kentheswaran, K., Ahmadi, A., Teychené, J., Bessière, Y., Alfenore, S., Laborie, S., Bastoul, D., Loubière, K., Guigui, C., Sperandio, M., Barna, L., Paul, E., Cabassud, C., Liné, A., \& Hébrard, G. (2020). Attempts, successes, and failures of distance learning in the time of COVID-19. Journal of Chemical Education, 97(9), 2448-2457. https://doi.org/10.1021/acs.jchemed.0c00717.

Donovan, J. J., \& Radosevich, D. J. (1999). A meta-analytic review of the distribution of practice effect: Now you see it, now you don't. Journal of Applied Psychollogy, 84(5), 795-805.

Dunn, T. J., Baguley, T., \& Brunsden, V. (2014). From alpha to omega: A practical solution to the pervasive problem of internal consistency estimation. British Journal of Psychology, 105(3), 399-412. https://doi. org/10.1111/bjop.12046. 
Ebbinghaus, H. (1964). Memory: A contribution to experimental psychology (H. A. Ruger, C. E. Bussenius Trans.). New York: Dover. (Original work published 1885)

Erzen, E. (2017). The effect of anxiety on student achievement. In E. Karadag (Ed.), The Factors Effecting Student Achievement (pp. 75-94). Springer International Publishing. https://doi.org/10.1007/978-3-31956083-0 5.

Faul, F., Erdfelder, E., Lang, A.-G., \& Buchner, A. (2007). G*power 3: A flexible statistical power analysis program for the social, behavioral, and biomedical sciences. Behavior Research Methods, 39(2), 175191. https://doi.org/10.3758/BF03193146.

Giofrè, D., Borella, E., \& Mammarella, I. C. (2017). The relationship between intelligence, working memory, academic self-esteem, and academic achievement. Journal of Cognitive Psychology, 29(6), 731-747. https://doi.org/10.1080/20445911.2017.1310110.

Greene, R. L. (1989). Spacing effects in memory: Evidence for a two-process account. Journal of Experimental Psychology: Learning, Memory, and Cognition, 15(3), 371-377. https://doi.org/10.1037/ 0278-7393.15.3.371.

Griefahn, B., Künemund, C., Bröde, P., \& Mehnert, P. (2001). Zur Validität der deutschen Übersetzung des Morningness- Eveningness-Questionnaires von Horne und Östberg. Somnologie, 5, 71-80.

Hair, P., \& Hampson, S. E. (2006). The role of impulsivity in predicting maladaptive behaviour among female students. Personality and Individual Differences, 40(5), 943-952. https://doi.org/10.1016/j.paid.2005.10. 002 .

Horton, N. J., \& Kleinman, K. P. (2007). Much ado about nothing. The American Statistician, 61(1), 79-90. https://doi.org/10.1198/000313007X172556.

Horzum, M. B., Önder, İ., \& Beşoluk, Ș. (2014). Chronotype and academic achievement among online learning students. Learning and Individual Differences, 30, 106-111. https://doi.org/10.1016/j.lindif. 2013.10.017.

James, G., Witten, D., Hastie, T., \& Tibshirani, R. (2013). An Introduction to Statistical Learning (Vol. 103). New York: Springer. https://doi.org/10.1007/978-1-4614-7138-7.

Janiszewski, C., Noel, H., \& Sawyer, A. G. (2003). A meta-analysis of the spacing effect in verbal learning: Implications for research on advertising repetition and consumer memory. Journal of Consumer Research, 30(ue 1), 138-149. https://doi.org/10.1086/374692.

Jensen, A. R. (1998). The $g$ factor: the science of mental ability. Westport, CT.

Kappe, R., \& van der Flier, H. (2012). Predicting academic success in higher education: What's more important than being smart? European Journal of Psychology of Education, 27(4), 605-619. https:// doi.org/10.1007/s10212-011-0099-9.

Kass, R. E., \& Raftery, A. E. (1995). Bayes factors. Journal of the American Statistical Association, 90(430), 773-795. https://doi.org/10.1080/01621459.1995.10476572.

King, F. J., Heinrich, D. L., Stephenson, R. S., \& Spielberger, C. D. (1976). An investigation of the causal influence of trait and state anxiety on academic achievement. Journal of Educational Psychology, 68(3), $330-334$.

Komarraju, M., Karau, S. J., \& Schmeck, R. R. (2009). Role of the big five personality traits in predicting college students' academic motivation and achievement. Learning and Individual Differences, 19(1), 4752. https://doi.org/10.1016/j.lindif.2008.07.001.

Kornell, N., Castel, A. D., Eich, T. S., \& Bjork, R. A. (2010). Spacing as the friend of both memory and induction in young and older adults. Psychology and Aging, 25(2), 498-503. https://doi.org/10.1037/ a0017807.

Laux, L., Hock, M., Begner-Köther, R., Hodapp, V., \& Renner, K. H. (2013). STADI Das State-Trait-AngstDepressions-Inventar. Göttingen: Hogrefe.

Lee, J., Song, H.-D., \& Hong, A. J. (2019). Exploring factors, and indicators for measuring students' sustainable engagement in e-learning. Sustainability, 11, 985. https://doi.org/10.3390/su11040985.

Lim, J. M. (2016). Predicting successful completion using student delay indicators in undergraduate self-paced online courses. Distance Education, 37(3), 317-332. https://doi.org/10.1080/01587919.2016.1233050.

Lo, C. C. (2010). How student satisfaction factors affect perceived learning. Journal of the Scholarship of Teaching and Learning, 10(1), 47-54.

Lounsbury, J. W., Sundstrom, E., Loveland, J. M., \& Gibson, L. W. (2003). Intelligence, "big five" personality traits, and work drive as predictors of course grade. Personality and Individual Differences, 35(6), 1231-1239. https://doi.org/10.1016/S0191-8869(02)00330-6.

Lust, G., Elen, J., \& Clarebout, G. (2013). Students' tool- use within a web enhanced course: Explanatory mechanisms of students' tool-use pattern. Computers in Human Behavior, 29(5), 2013-2021. https://doi. org/10.1016/j.chb.2013.03.014. 
Maldonado-Mahauad, J., Pérez-Sanagustín, M., Kizilcec, R. F., Morales, N., \& Munoz-Gama, J. (2018). Mining theory-based patterns from big data: Identifying self-regulated learning strategies in massive open online courses. Computers in Human Behavior, 80, 179-196. https://doi.org/10.1016/j.chb.2017.11.011.

Masui, C., Broeckmans, J., Doumen, S., Groenen, A., \& Molenberghs, G. (2014). Do diligent students perform better? Complex relations between student and course characteristics, study time, and academic performance in higher education. Studies in Higher Education, 39(4), 621-643. https://doi.org/10.1080/ 03075079.2012.721350.

Noftle, E. E., \& Robins, R. W. (2007). Personality predictors of academic outcomes: Big five correlates of GPA and SAT scores. Journal of Personality and Social Psychology, 93(1), 116-130. https://doi.org/10. 1037/0022-3514.93.1.116.

Plant, E. A., Ericsson, K. A., Hill, L., \& Asberg, K. (2005). Why study time does not predict grade point average across college students: Implications of deliberate practice for academic performance. Contemporary Educational Psychology, 30(1), 96-116. https://doi.org/10.1016/j.cedpsych.2004.06.001.

Poropat, A. E. (2009). A meta-analysis of the five-factor model of personality and academic performance. Psychological Bulletin, 135(2), 322-338. https://doi.org/10.1037/a0014996.

Preckel, F., Lipnevich, A. A., Boehme, K., Brandner, L., Georgi, K., Könen, T., Mursin, K., \& Roberts, R. D. (2013). Morningness-eveningness and educational outcomes: The lark has an advantage over the owl at high school. British Journal of Educational Psychology, 83(1), 114-134. https://doi.org/10.1111/j.20448279.2011.02059.x.

Pullmann, H., \& Allik, J. (2008). Relations of academic and general self-esteem to school achievement. Personality and Individual Differences, 45(6), 559-564. https://doi.org/10.1016/j.paid.2008.06.017.

Puzziferro, M. (2008). Online technologies self-efficacy and self-regulated learning as predictors of final grade and satisfaction in college-level online courses. American Journal of Distance Education, 22(2), 72-89. https://doi.org/10.1080/08923640802039024.

R Core Team (2019) R: A language and environment for statistical computing. R Foundation for Statistical Computing, Vienna. https://www.R-project.org/

Radovan, M. (2011). The relation between distance students' motivation, their use of learning strategies, and academic success. The Turkish Online Journal of Educational Technology, 10(1), 7.

Renner, K.-H., Hock, M., Bergner-Köther, R., \& Laux, L. (2016). Differentiating anxiety and depression: The state-trait anxiety-depression inventory. Cognition and Emotion, 32(7), 1409-1423. https://doi.org/10. 1080/02699931.2016.1266306.

Rohde, T. E., \& Thompson, L. A. (2007). Predicting academic achievement with cognitive ability. Intelligence, 35(1), 83-92. https://doi.org/10.1016/j.intell.2006.05.004.

Rothen, N., \& Meier, B. (2016). Time of day affects implicit memory for unattended stimuli. Consciousness and Cognition, 46, 1-6. https://doi.org/10.1016/j.concog.2016.09.012.

Schütz, A., \& Sellin, I. (2006). MSWS Multidimensionale Selbstwertskala. Göttigen: Hogrefe.

Schütz, A., Rentzsch, K., \& Sellin, I. (2017). MSWS. Multidimensionale Selbstwertskala. Göttingen: Hogrefe.

Schupp, J., \& Gerlitz, J.-Y. (2014). Big Five Inventory-SOEP (BFI-S). Zusammenstellung sozialwissenschaftlicher Items und Skalen (ZIS). https://doi.org/10.6102/zis54.

Silva, M., Dorso, E., Azhar, A., \& Renk, K. (2007). The relationship among parenting styles experienced during childhood, anxiety, motivation, and academic success in college students. Journal of College Student Retention: Research, Theory \& Practice, 9(2), 149-167. https://doi.org/10.2190/CS.9.2.b.

Stadtfeld, C., Vörös, A., Elmer, T., Boda, Z., \& Raabe, I. J. (2019). Integration in emerging social networks explains academic failure and success. Proceedings of the National Academy of Sciences, 116(3), 792797. https://doi.org/10.1073/pnas.1811388115.

Strenze, T. (2007). Intelligence and socioeconomic success: A meta-analytic review of longitudinal research. Intelligence, 35(5), 401-426.

Tabibian, B., Upadhyay, U., De, A., Zarezade, A., Schölkopf, B., \& Gomez-Rodriguez, M. (2019). Enhancing human learning via spaced repetition optimization. Proceedings of the National Academy of Sciences, 116(10), 3988-3993. https://doi.org/10.1073/pnas.1815156116.

Tangney, J. P., Baumeister, R. F., \& Boone, A. L. (2004). High self-control predicts good adjustment, less pathology, better grades, and interpersonal success. Journal of Personality, 72(2), 271-322.

Tias, P. A., Istamar, S., Atmoko, A., \& Corebima, A. D. (2015). The contribution of intelligence quotient (IQ) on biology academic achievement of senior high school students in Medan, Indonesia. International Journal of Educational Policy Research and Review, 2(10), 141-147.

Toppino, T. C., \& Bloom, L. C. (2002). The spacing effect, free recall, and two-process theory: A closer look. Journal of Experimental Psychology: Learning, Memory, and Cognition, 28(3), 437-444. https://doi.org/ 10.1037/0278-7393.28.3.437. 
Touron, J. (1983). The determination of factors related to academic achievement in the university: Implications for the selection and counselling of students. Higher Education, 12(4), 399-410. https:// doi.org/10.1007/BF00158243.

Trapmann, S., Hell, B., Hirn, J, O, W., \& Schuler, H. (2007). Meta-analysis of the relationship between the big five and academic success at university. Zeitschrift Für Psychologie / Journal of Psychology. https://doi. org/10.1027/0044-3409.215.2.132

Valentine, J. C., DuBois, D. L., \& Cooper, H. (2004). The relation between self-beliefs and academic achievement: A meta-analytic review. Educational Psychologist, 39(2), 111-133. https://doi.org/10. 1207/s15326985ep3902 3.

van Buuren, S., \& Groothuis-Oudshoorn, K. (2011). Mice: Multivariate imputation by chained equations in R. Journal of Statistical Software, 45(3), 1-67.

Venables, W. N., \& Ripley, B. D. (1994). Modern applied statistics with S. New York: Springer.

Vermeulen, L., \& Schmidt, H. G. (2008). Learning environment, learning process, academic outcomes and career success of university graduates. Studies in Higher Education, 33(4), 431-451. https://doi.org/10. 1080/03075070802211810.

Viberg, O., Khalil, M., \& Baars, M. (2020). Self-regulated learning and learning analytics in online learning environments: A review of empirical research. Proceedings of the tenth international conference on learning analytics \&amp; knowledge, 524-533. https://doi.org/10.1145/3375462.3375483.

Walberg, H. J. (1984). Improving the productivity of America's schools. Educational Leadership, 41, 19-27.

Weiss, R. (2006). Grundintelligenztest Skala 2-Revision (CFT 20-R) mit Wortschatztest und Zahlenfolgentest-Revision (WS/ZF-R). Göttingen: Hogrefe.

York, T. T., Gibson, C., \& Rankin, S. (2015). Defining and measuring academic success. Practical Assessment, Research \& Evaluation, 20(5), 1-20. https://doi.org/10.7275/hz5x-tx0.

Zhu, Y., Au, W., \& Yates, G. (2016). University students' self-control and self-regulated learning in a blended course. The Internet and Higher Education, 30, 54-62. https://doi.org/10.1016/j.iheduc.2016.04.001.

Publisher's note Springer Nature remains neutral with regard to jurisdictional claims in published maps and institutional affiliations. 